\title{
Do memorability ratings affect study-time allocation?
}

\author{
GIULIANA MAZZONI, CESARE CORNOLDI, and GIAMPIERA MARCHITELLI \\ Università di Padova, Padua, Italy
}

\begin{abstract}
This research addresses the relation between predicting future memory performance (judgment of learning, or JOL) and subsequent self-paced study-time allocation. The results of three experiments support the main hypotheses: (1) recall increases with increasing JOL, (2) restudy increases JOL accuracy, and (3) study time is related to JOL. This last relation depends on the length of initial presentation time of the items. When the initial exposure trials were short, the most restudy time was allocated to the items judged hard to recall, but when the initial exposure times were long, the most restudy time was allocated to the uncertain items. Items studied longer were recalled equally well (Experiments 1 and 3) or to a lesser extent (Experiment 2) than items studied for a shorter time. It is hypothesized that during study time, subjects refine their JOLs for the items initially less well discriminated.
\end{abstract}

This article deals with the extent to which adults are able to predict memory performance and how these memory predictions may affect subsequent study and recall of the items.

The ability to predict future memory performance is an important aspect of the monitoring and control of cognitive processes and, as such, is one of the key components of metamemory (Brown, 1978; Schneider, 1985). For example, judgments of the ease of learning (Underwood, 1964, 1966), the feeling of knowing (Hart, 1965; Nelson, Leonesio, Shimamura, Landwehr, \& Narens, 1982), or judgments of learning (King, Zechmeister, \& Shaughnessy, 1980) typically predict subsequent performance with above-chance accuracy (for a review, see Nelson, 1988).

The last type of monitoring judgments, called either judgments of learning (JOL) or judgments of knowing, refers to predictions made during or immediately after the learning phase. Like the other measures of metacognition, JOLs represent an attempt to predict future memory performance of the items being learned, and they have been found to be more accurate than chance in predicting both subsequent recognition (Gardiner \& Klee, 1976; Groninger, 1979) and subsequent recall performance (Arbuckle \& Cuddy, 1969; Lovelace, 1984). Most of the research using JOLs has used methodologies that may help in finding an accuracy effect. In our opinion, prediction can be facilitated in paired associates or in recognition tests because these paradigms permit the subjects to test their memory (on the basis of the available cues) before predicting an item's memorability. Furthermore, in

\footnotetext{
This research was partially supported by a CNR grant. We are deeply indebted to T. O. Nelson for the great help in reviewing the manuscript, and to $S$. Bettella for preparing the computer programs. Requests for reprints may be addressed to Giuliana Mazzoni, Dipartimento di Psicologia Generale, Piazza Capitaniato 3, 35100 Padua, Italy.
}

some cases, items were employed that varied in characteristics such as association value, pronouncability, frequency, imagery value, concreteness, and meaningfulness (Groninger, 1979; Lovelace, 1984; Underwood, 1966). It is reasonable to assume that subjective judgments do reference to such dimensions. If so, JOLs of relatively homogeneous items would not be expected to predict subsequent recall. The first aim of our research, therefore, was to assess JOL accuracy in predicting recall in a freerecall task when stimuli were relatively homogeneous.

Another important reason for studying monitoring judgments is to discover how monitoring interacts with other aspects of cognition. For example, Pressley, Levin, and Ghatala (1984) showed that the monitoring system plays a critical role for choosing a more efficient strategy. Reder (1987) found that the choice between a direct versus an inferential search path is guided by a very quick feelingof-knowing judgment at the beginning of the retrieval phase. Moreover, monitoring the presence of the required information in memory is a prerequisite for continuing the retrieval process (Koriat \& Lieblich, 1977); otherwise, a very quick " don't know" answer (Glucksberg \& McCloskey, 1981) is likely to terminate the memory search for that item.

The influence of memory monitoring on the use of strategies has been construed as a relation between knowledge of the task, induced by the experimenter, and choice of the best strategy (Kestner \& Walter, 1977; Mazuryk \& Lockhart, 1974; Shaughnessy, 1981). Memorability ratings have been linked to "effort allocation" during the retrieval phase in both adults and children (Posnansky, 1978; Wellman, 1979), with items that are judged hard to recall receiving greater effort than those judged easy to recall.

In a learning task, the amount remembered increases, at a decreasing rate, with study time. When study time is experimentally paced, items studied for a longer time 
are recalled better than items studied for a shorter time (Murdock, 1974; Waugh, 1967). When study time is self-paced, subjects from the age of 10 upward tend to study items either not previously recognized (Rogoff, Newcombe, \& Kagan, 1974) or not previously recalled (Masur, McIntyre, \& Flavell, 1973). Furthermore, when self-paced, subjects study for a longer time items generally found to be difficult to recall than items generally found to be easy to recall (Zacks, 1969). All of the above studies suggest that subjects-at least adults-monitor their knowledge of the to-be-learned material in advance of and during learning, and that they can use the products of their monitoring as a basis for allocating study time. If we suppose that someone has a learning goal, then the amount of the time devoted to study should be related both to the goal and to the prelearning state of the item. Thus, an item subjectively judged to be difficult to remember should be studied longer than an item judged to be easy to remember.

Therefore, we hypothesize that the amount of time devoted to self-paced study depends on (and is thus related to) the subject's JOL. This relation may change, however, if the subject has already had the opportunity to inspect the items and to develop the belief that he or she would not have enough time to learn every item in a list. In this case, the subject presumably would modify his or her strategy by shifting the most study time from items judged difficult to recall to items with an intermediate level of recallability.

Suppose we assume that memory predictions are perfect predictions of subjective memorability. Study-time allocation strategy, then, might affect subsequent recall performance in at least two ways: (1) extra study time for the more difficult items than for easier ones should at least partially compensate for initial differences in item difficulty, and (2) when memorability predictions (JOLs) are equal, items studied for a longer time should be recalled better than items studied for a shorter time because additional study time should improve recall (Waugh, 1967). However, if we assume that memory predictions are only partially correct, and are progressively refined during study, the amount of study time could be influenced by the difficulty of studying the items. In other words, items with the same rating can differ in their degree of learning difficulty; items that are more difficult, independent of their rating, could be studied for a longer time. In this case, more study time would not necessarily imply better recall.

In conclusion, our research explored evidence for three general hypotheses regarding metacognitive monitoring and control while items are being learned: (1) people are able to assess the ease of recalling items even when the items are relatively homogeneous in rated imageability and frequency of occurrence; (2) study time is directly related to predicted difficulty of recall, hence study time increases with rated difficulty of recall; and (3) recall is directly related to study time; therefore, if subjects use more time to study items deemed to be hard to recall, the memory disadvantage of these items should be at least par- tially eliminated. Furthermore, items with equivalent memorability ratings should be recalled in direct relation to the length of time they are studied.

To test these hypotheses, we conducted a series of experiments in which JOL accuracy was assessed for a set of nouns with reasonably comparable imageability ratings. In Experiment 1, study-time allocation was assessed for items with different JOLs. In Experiments 2 and 3, we explored the study-time-recall relation when the initial presentation times or materials were manipulated. In particular, the results of Experiment 1 induced us to ask whether a subject's metacognitive activity would change with variations in presentation time. We expected that a longer presentation time would lead to a better evaluation of the real chances of remembering, leading subjects to focus more on items easy to recall. For this reason, subjective strategy of time allocation may be different, depending on the presentation time.

\section{EXPERIMENT 1}

\section{Method}

Subjects. Thirty-eight university students, mostly females, participated in the experiment. The subjects were randomly assigned to two groups. They attended a course in psychology, and their age ranged between 20 and 30 years.

Material. Ninety concrete, unrelated Italian nouns were chosen from the pool of words in the Bortolini, Tagliavini, \& Zampolli (1972) frequency norms for the Italian language. The frequency norms were computed from 500,000 occurrences, using various samples of written (books, newspapers, and journals) and spoken (screenplays) Italian language. The 90 nouns were chosen among those ranging from 5 to 70 per 500,000 in frequency, and with an imagery value higher than 6.00 on a 7-point scale. Imagery value was scored following the Paivio, Yuille, and Madigan (1968) procedure, by which a group of judges rates the ease for a noun to evoke an image, using the lowest point (1) when the noun does not evoke any image, and the highest point (7) when a very vivid image is generated with facility. To find 90 unrelated nouns with the predefined imagery characteristics, it was necessary to examine nouns with frequency occurrences ("valore d'uso") between 5 and 70 , which correspond to the ranks $447-3,009$ for Italian words. The 90 nouns were randomly assigned to two lists of 40 nouns each, and to a warm-up list of 10 nouns.

Design. Type of task, with two levels-rating only and rating plus study - was the within-subjects factor. Order of presentation of the two tasks was balanced across subjects, and was considered a between-subjects factor. This design was used because the ratingplus-study task might induce a carryover effect on the rating-only task. The subjects with the rating task presented first were called the rating-study (RS) group and were considered sensitized to the study, having received not only instructions, but also a recall task before the study phase. The subjects with the rating-plus-study task presented first were called the study-rating (SR) group. Lists were balanced across tasks. Thus, half of the subjects in each group had List 1 for the rating-only task, and the other half had List 2.

Procedure. All subjects were tested individually and were informed about the general aspects of all phases of the experiment, including the final recall phase (i.e., intentional learning tasks), and about the list length. Before each task (rating only and rating plus study), the subjects had a warm-up with the 10 nouns of the warmup list. Thus, before accomplishing each task, the subjects knew exactly the procedure. In the rating-only task, the $\mathbf{4 0}$ nouns of a list were presented on a computer screen, one noun at a time, for $8 \mathrm{sec}$ each. Then the word was automatically replaced by a line, 
representing an equal-interval 5-point rating scale. The scale remained visible for $5 \mathrm{sec}$, during which the subjects made their JOL. A rating of 5 indicated that they were almost certain to be able to recall the word in the subsequent recall phase, 4 indicated they were rather certain to be able to recall it, 3 indicated they were uncertain about subsequent recall, 2 indicated they were rather sure they would not be able to recall the word, and 1 indicated they were almost sure they would not be able to recall it. The rating was made by pushing the corresponding numerical key on the computer keyboard, and the chosen rating appeared on the screen. Then, after a 2 -sec pause, a new word appeared. Nouns were presented in a different random order for each subject. At the end of the list presentation, the subjects performed an interference task for $30 \mathrm{sec}$, in which they had to count backward by threes from a three-digit number, to help minimize recency effects. Then the subjects had $120 \mathrm{sec}$ for written recall.

In the rating-plus-study task, the first part was exactly the same as the rating task described above. Then, immediately after completing rating all items, the words were shown again for a maximum of $10 \mathrm{sec}$ in the same order as in the rating task. Before starting with the rating-plus-study phase, the subjects were informed that this was a self-paced study time and that they should use this time to study the items prior to the final recall task. They were also told not to waste time, because the overall time required for the study was also considered a measure of performance. The subjects could interrupt the study whenever they wanted, by pushing any computer key, whereupon the word being studied was replaced, after a 2 -sec pause, by the next word. Upon finishing the self-paced study phase, the subjects went through the arithmetic task and then had $120 \mathrm{sec}$ for written free recall. In both tasks, rating scores and study times were computer-recorded. After the experiment, a brief, informal posttest interview was conducted.

\section{Results}

Data on recall are presented first, followed by data on study time. Because several subjects did not use the lowest and highest scores on the scale values ( 1 and 5), we combined words rated 5 with those rated 4 , and words rated 1 were combined with those rated 2 . In addition, 1 subject in the RS group and 3 subjects in the SR group were excluded from the analyses, 3 of them for having missed one of the remaining three ratings, and 1 for idiosyncratic use of the scale.

Figure 1 shows the percentage of words recalled at each of the three rating levels, with respect to test and groups (order of tasks). As mentioned earlier, this latter distinction was introduced because doing the rating-only task first might modify subsequent performance. A mixed design 2 (groups) $\times 2$ (tasks) $\times 3$ (ratings) analysis of variance (ANOVA) was computed on recall percentages, after an arcsin transformation. In general, the percentage of words recalled correctly increased with the memorability ratings, with higher recall for items judged easier to remember $[F(2,64)=23.22, p<.001]$. The interaction of groups $\times$ task and the interaction of groups $\times$ tasks $\times$ ratings were both significant. This result is due to the high recall in the SR group for studied nouns rated 1 or $2 .{ }^{1}$ However, with the exception of words rated 1 or 2 in the nonsensitized-for-study group (with rating plus study presented as the first task), items in the rating-plus-study condition rated as easier to remember were recalled better.
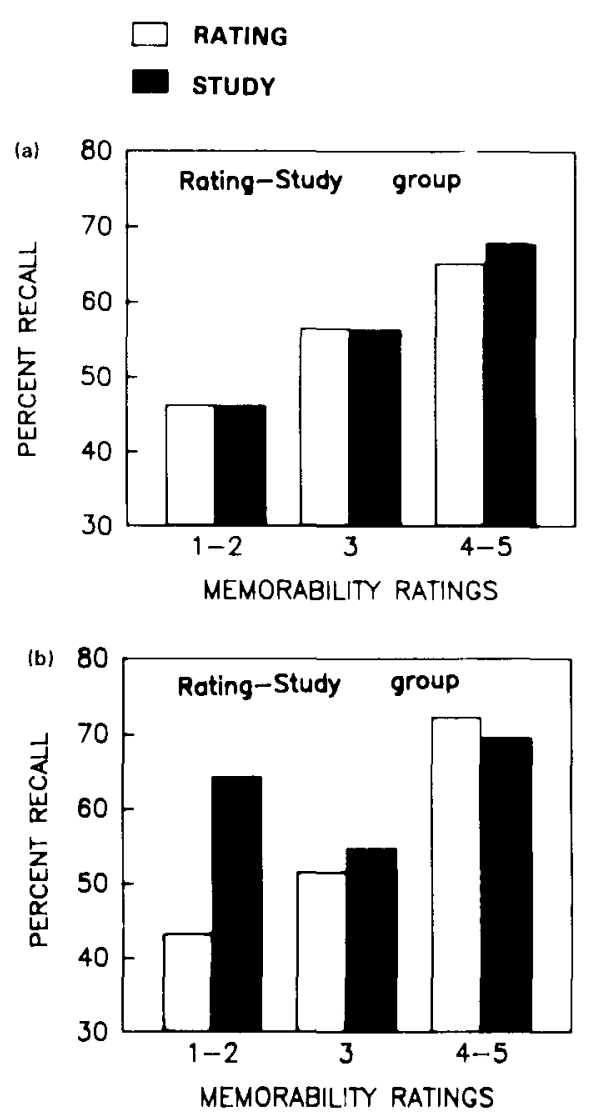

Figure 1. Percentage of recalled words with respect to the three JOL ratings in the rating-only and rating-plus-study tasks in (a) the rating-study group and (b) the study-rating group in Experiment 1.

Data on study-time allocation are presented in Figure 2. Three more subjects who used the maximum available times for all the items are not included in these analyses.

Figure 2 shows the mean restudy time for the three rating scores and for recalled and nonrecalled words; the

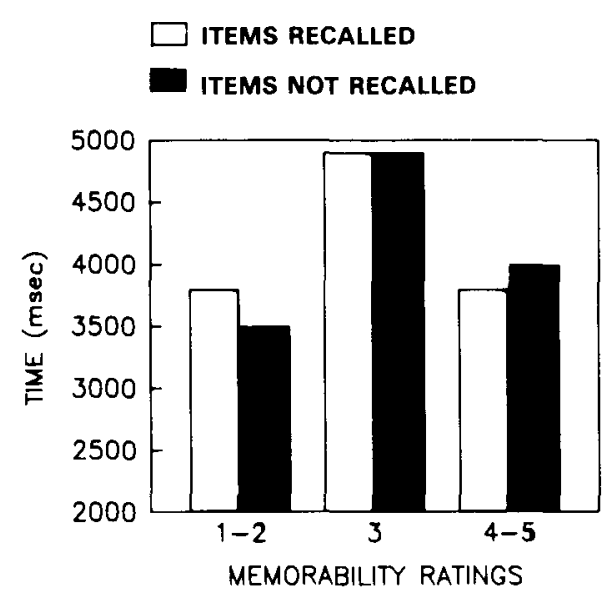

Figure 2. Means of individual mean restudy times (in msec) for recalled and nonrecalled nouns with respect to their JOLs in Experiment 1. 
data are collapsed across groups, because no significant effect (either main or interactive) affecting the order of presentation of the tasks (groups) was found. The subjects of both groups devoted more time to studying words rated as uncertain (3) than to those rated as having low $(1-2)$ or high (4-5) memorability ratings $[F(2,58)=8.64$, $p<.001]$. There was no difference between time allocated to studying words later recalled and time allocated to words not recalled $[F(1,29)=0.71]$.

\section{Discussion}

To summarize, the results indicate that subjects discriminate among items and that items rated as easier to recall are better recalled than items rated as hard to recall. The latter result is in accord with the notion that frequency and imagery values are not the only components affecting judgments (Groninger, 1979; Underwood, 1966).

The assessment of study-time allocation and self-paced study efficacy showed that, overall, the subjects allocated more time to items rated as uncertain than to the other items. One possible reason for subjects to choose this strategy is that items rated as uncertain are closer to a "recallability" (JOL) threshold, and spending time on them is considered to be worthwhile. Some items are over the threshold and, being judged as recallable, are studied for a very short time; other items are slightly under the threshold (i.e., those judged as uncertain), and subjects may judge them as easier to bring over the threshold than those judged as very difficult to remember. Thus, in some cases, subjects may decide to study items judged to be intermediate in difficulty longer than items judged to be difficult to remember.

Suppose that initial exposure time for items is so limited that the recallability of the items is difficult to judge, except for obviously easy or difficult ones. We might expect subjects to spend more study time on the less recallable items than on uncertain items. This expectation was tested in Experiment 2.

In Experiment 1, we assessed the study efficacy in compensating for initial differences in recallability by comparing the time spent restudying recalled versus nonrecalled words. If ratings are equal, recalled items should have been restudied for more time than nonrecalled items, because additional study time should help compensate for the recallability imbalance. However, we found that recalled and nonrecalled items were restudied for the same amount of time. In addition, items studied longer (those rated 3) did not reach the same level of recall as items judged easy to recall (4-5). In the restudy condition, the number of items recalled did not increase. It is possible that in the conditions of Experiment 1, study time did not completely compensate for the initial difference in recallability. One explanation for these results is that the subjects used some of the relatively long presentation time to study the items. If this occurred, the times allocated to presentation and to study would be partially confounded, making it difficult to separate the role of the two factors. In Experiment 2, we minimized this confound- ing effect by shortening the presentation time to $2.5 \mathrm{sec}$, a time too brief to permit much study.

\section{EXPERIMENT 2}

Experiment 2 was designed to answer several questions. First, the presentation time was diminished in order to examine whether the allocation of study time among ratings found in Experiment 1 was due to the possibility of studying the items during the presentation time. Second, the prediction that a shortened presentation time would induce allocation of study time to difficult-to-recall words was tested. Finally, the possibility that self-paced study time can increase JOL accuracy was assessed by introducing a second rating after the study. Previous research has shown that JOL accuracy increases with study trials. Thus, in this case, we expected that after the self-paced study, subjects would be better able to discriminate among subsequently recalled and nonrecalled items.

\section{Method}

Subjects. The participants were 19 psychology students, mostly females, whose ages ranged between 20 and 30 years, and who had no previous experience in this kind of task.

Design and Procedure. List 1 and the warm-up list of Experiment 1 were used in this experiment. All of the subjects were presented with one task, divided into two parts, and presented in the same order to all subjects. The procedure was the same as in the rating-plus-study condition in Experiment 1, with the only differences being (1) a shorter presentation time and (2) a second rating phase, which occurred after the self-paced study phase. Thus, the task can be summarized as follows. Each of the 40 nouns of the list was presented for $2.5 \mathrm{sec}$ on the computer screen, replaced after that time by the 5-point rating scale described above for Experiment 1 . After completing the rating of all 40 nouns, each noun appeared again on the screen for a maximum of $10 \mathrm{sec}$, during which the subjects could interrupt the study time by pressing any key. Next, the rating scale was presented on the screen and the subjects again rated the likelihood of recalling the just-studied noun. Then the subjects studied and rated the next word, and so on for 40 words. Next, the 30-sec arithmetic task occurred, as in Experiment 1, followed by written free recall for $120 \mathrm{sec}$.

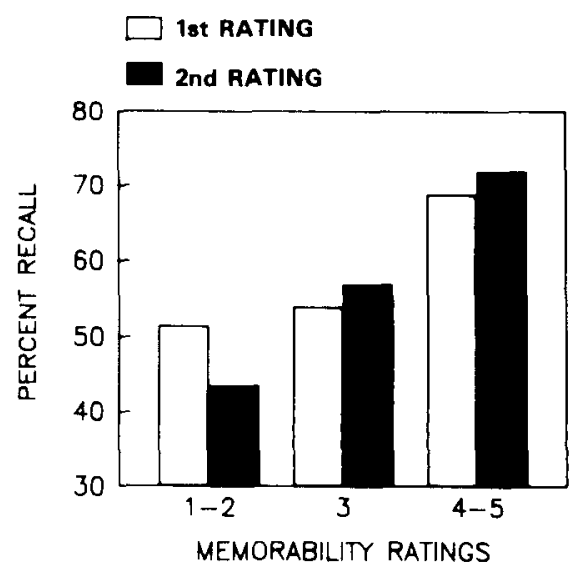

Figure 3. Percentage of recalled nouns with respect to JOLs in the first and second rating phase in Experiment 2. 
As in Experiment 1, the subjects were informed of the list length and of all the phases of the experiment; nouns were presented in a different random order for each subject, and ratings and study times were computer-recorded.

\section{Results}

Data on recall are presented first. Percentages of recall for words rated as easy (4-5), intermediate (3), and hard to remember $(1-2)$ are shown in Figure 3 . Open bars show recall percentages for the JOLs made before study; filled bars show recall percentages for the JOLs made after study. The relation between recall and rating follows the pattern observed in the rating-only condition in Experiment 1 , in which words rated as difficult to recall were less well remembered, and recall increased with an increase in JOL. The within-subjects ANOVA on recall in the three ratings showed a significant main effect for ratings $[F(2,36)=17.31, p<.001]$. Predictions seem to have been more discriminative after the study opportunity. We carried out a mixed design ANOVA on the mean ratings given in the two rating phases for recalled and nonrecalled words. Ratings after restudy were more accurate in predicting subsequent recall, as shown by the significant interaction $[F(1,19)=13.29, p<.01]$. Planned comparisons showed that the accuracy increase is due to a better discrimination of the items judged difficult to recall (recall percentage dropped from $52 \%$ to $43 \%$ ).

If subjects allocate more study time to items initially judged to be difficult to remember than to those judged more memorable, restudy time should decrease as memorability ratings increase. As shown in Figure 4, studytime allocation followed this pattern. Items judged as less memorable were studied longer than those rated as uncertain, and the latter turned out to be studied longer than the easiest items. This pattern was significant $[F(2,32)=$ $5.7, p<.05$ ], based on a $2 \times 3$ ANOVA on study times as function of recall and ratings ( 2 subjects were excluded from the analyses for having used the maximum time for all the items). The main effect of recall was also signifi-

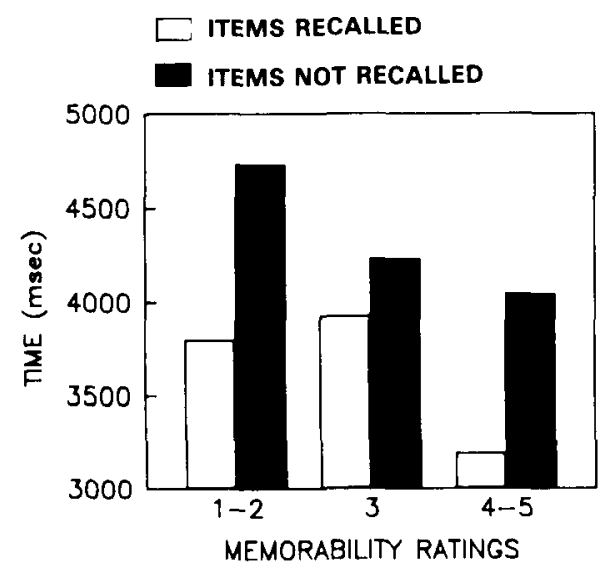

Figure 4. Means of individual mean restudy times (in msec) with respect to JOLs in the first rating phase, and success in recall in Experiment 2. cant $[F(1,16)=11.16, p<.005]$. Nonrecalled words were studied longer $(4,338 \mathrm{msec})$ than recalled words $(3,645 \mathrm{msec})[F(1,16)=11.16, p=.004]$.

\section{Discussion}

Unsurprisingly, JOLs were more accurate after studying the items than before studying them. Two conclusions can be drawn from this result: (1) JOL is based, at least in part, on the learning process and, after restudy, judgments of recall are more accurate, either because they are based on the learning activity itself or because after restudy, the state of the item is more clear to the subject; and (2) JOLs are not static judgments; rather, they are dynamically updated as learning proceeds. Both conclusions are in agreement with previous results (Leonesio \& Nelson, 1988; Lovelace, 1984), in which JOL was found to be based on learning activity and to be more accurate for overlearned items. Furthermore, the recall percentages for the three ratings are very similar to those obtained in Experiment 1, confirming the stability of the JOL-recall relation.

The second result is that changing the initial presentation time of a word leads to a change in the study-time allocation pattern. Reducing the presentation time from $8 \mathrm{sec}$ (Experiment 1) to $2.5 \mathrm{sec}$ (Experiment 2) induced the subjects to allocate the most time to studying items judged as most difficult, with time allocation increasing systematically as recallability judgments decreased. Thus, the original presentation time can influence the study strategy chosen by the subjects. One way of explaining this result is to suppose that greater accuracy in the rating occurs after a longer presentation time (a longer time could itself be responsible for a clearer status of the item to be rated). If so, ratings should more accurately predict recall in Experiment 1 than in Experiment 2 because the former experiment included a longer presentation time than the latter. The trend is in the expected direction for the low-rated items. With a short initial presentation time, the discrimination of the hard-to-remember items may be less clear, and therefore subjects may devote more time to studying them.

A third finding is a partial replication of the failure of extra study time to compensate completely for the initial recallability disadvantage of some items. Here, nonrecalled words were studied longer than recalled words, for all three ratings.

In Experiment 3, we tested the effects of three different presentation times on the study-recall relation using sentences rather than individual words. This more "naturalistic" material might be useful for generalizing to the everyday use of study time in real-life situations.

\section{EXPERIMENT 3}

\section{Method}

Subjects. Forty-two university students, predominantly female, between 20 and 30 years old, participated in this experiment. They were attending a psychology course at the University of Padua. 
Design and Material. Presentation time was manipulated between subjects, forming three groups of subjects, with $2.5,5$, and $7.5 \mathrm{sec}$ of exposure, respectively. The groups underwent the same procedure as in Experiment 2.

Forty transitive sentences were used in this experiment. The sentences were made by using the nouns chosen for the first experiment [similar in frequency value (average) and imagery value (high)] and connecting them with a verb. Verbs were chosen from those in the Bortolini et al. (1972) frequency norms, with frequency occurrences comparable to those used for the nouns. The sentences were constructed so as to avoid stereotyped Italian sentences (i.e., the subjects could not infer the verb from the subject of the sentence, and could not infer the object after reading the subject-verb part of the sentence), but were easily understandable and were not bizarre. Some examples of the sentences are: "The bride drinks coffee," and "The policeman folds the newspaper."

Procedure. The subjects were tested individually. The sentences were presented on a computer screen for $2.5 \mathrm{sec}$ to the first group of subjects, for $5 \mathrm{sec}$ to the second group, and for $7.5 \mathrm{sec}$ to the third. Presentation order was completely randomized. The subjects were instructed to look at the sentences during the presentation time, and to give their recallability rating, with respect to a verbatim recall test, when the sentence was over and the rating scale was shown on the computer screen. Ratings and the rating procedure were identical to those of Experiments 1 and 2. After completing the rating task for the entire list, the subjects were informed that they had a 15-sec maximum time for restudying the sentences, which would be shown again one at a time in the same order as in the rating task. They were informed about the self-paced restudy procedure, in that they could interrupt their study when they decided. As in the previous experiments, the subjects were instructed to use this time to increase their subsequent recall of the items. A 15-sec maximum time period for study was chosen instead of the $10 \mathrm{sec}$ used in the previous experiments because a preliminary test showed that $10 \mathrm{sec}$ was not enough time for this material. A second 5-point rating scale was shown on the screen after the subject restudied each sentence, and the subjects were instructed to give another memorability rating about the sentence. When restudy-rerating of the whole list was finished, the subjects were given a $30-\mathrm{sec}$ arithmetic task, followed by written free recall for $5 \mathrm{~min}$.

\section{Results}

Data on recall are reported first. Only perfectly (verbatim) recalled sentences were considered as correct responses. The percentages of recall for the three ratings are collapsed across groups, because an ANOVA showed that slight differences across the three presentation-time groups were not significant and that different presentation times did not differentially affect the pattern of JOLs. The percentages (Figure 5) are similar to those obtained in the previous experiments $(51 \%, 57 \%$, and $68 \%)$, showing that recall was higher for sentences with a higher memorability rating. A 2 (rating phase) $\times 3$ (ratings) ANOVA confirmed the difference in recall among ratings $[F(2,54)=$ $8.44, p<.001]$. Furthermore, recalled items had significantly higher ratings than did nonrecalled items $[F(1,27)=$ $13.52, p<.001]$. There was a tendency toward increasing JOL accuracy after restudy, with better discrimination of items judged hard to recall ( $51 \%$ vs. $42 \%$ ). However, the improvement in the second rating phase was less evident than that obtained in Experiment 2. The interaction of rating phase with recall was not significant $[F(1,27)=2.29, p=.13]$.

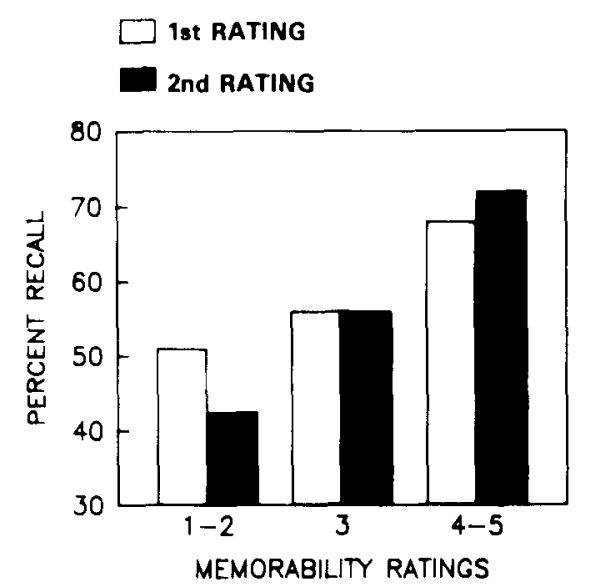

Figure 5. Percentage of recalled sentences with respect to JOLs in the first rating phase of Experiment 3.

Distribution of study times is shown in Figure 6. Overall, times were different across ratings $[F(2,42)=4.19$, $p<.02]$, but not across groups $[F(2,21)=0.864]$. Although the interaction of groups $\times$ ratings was not significant $[F(4,42)=0.75]$, inspection of Figure 6 shows a pattern of data corresponding to our prediction. With a short presentation time $(2.5 \mathrm{sec})$, more study time was allocated to items judged difficult to remember (as found in Experiment 2), and a similar, though less evident, trend is present in the 5-sec presentation-time group. On the contrary, with a longer presentation time, there is no clear difference in study times for items rated 1-2, 3, and 4-5. The only difference with respect to the other groups ap-

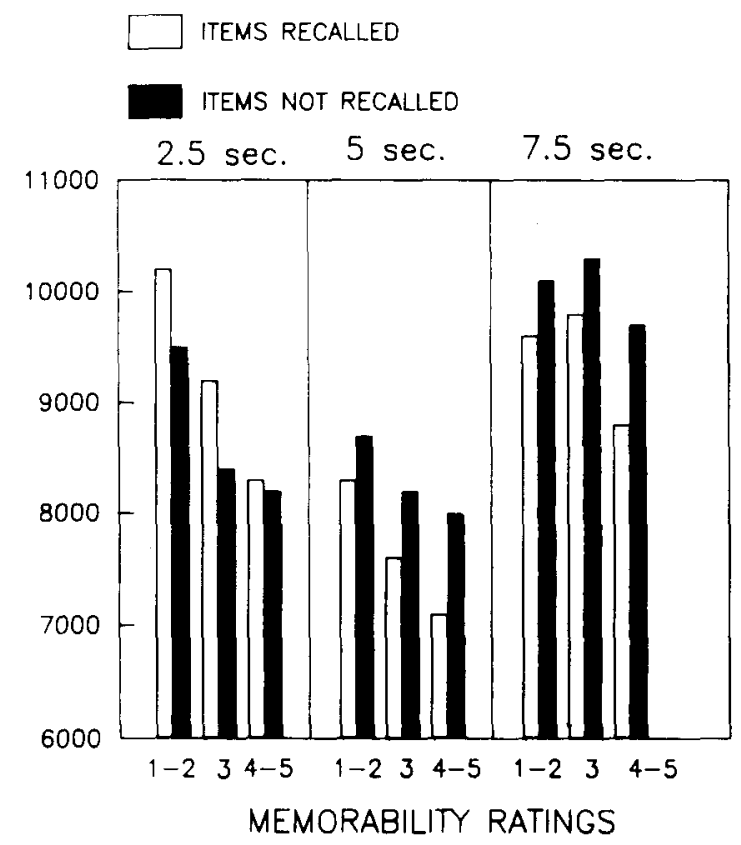

Figure 6. Means of individual mean restudy times (in msec) for recalled and nonrecalled sentences with respect to the first JOL in Experiment 3. Restudy times are shown for sentences with an initial exposure time of $2.5,5$, and $7.5 \mathrm{sec}$. 
pears to be the greater quantity of time devoted to the items rated as uncertain. A conservative post hoc (Tukey) test showed that significantly more time was allocated to items rated as uncertain by the group with $7.5 \mathrm{sec}$ of presentation time, relative to the other groups $(p<.05)$. As in Experiment 1, no difference was found in the mean amount of study time allocated to recalled $(8,769 \mathrm{msec})$ and nonrecalled $(9,076 \mathrm{msec})$ items $[F(1,21)=1.42]$.

\section{Discussion}

The percentages of sentences recalled for each rating score are similar to those found in the previous experiments, in which more simple and homogeneous material was used, demonstrating that the ability to judge easyversus hard-to-recall items seems to be relatively stable across subjects, tasks, and material.

Increasing the level of complexity of the material did not cause an increase in the compensating benefit of restudy time, because recalled sentences were studied as long as nonrecalled ones. The presentation time did not affect this result. However, with a $7.5-\mathrm{sec}$ presentation time, the amount of study time allocated to the items rated as uncertain was higher than in the other groups, giving partial confirmation to the hypothesis that the amount of initial presentation time is a relevant factor in selecting a time-allocation strategy.

\section{GENERAL DISCUSSION}

Three experiments were performed to examine the following points: (1) JOL discrimination of rather homogeneous material, (2) if and how study time influences JOL, (3) the relation between JOL and study-time allocation, and (4) the influence of self-paced study time on subsequent recall.

In the first experiment, we compared recall performance after a rating-only task with performance after rating plus study. Recall tended to increase with increased memorability ratings (JOLs); subjects recalled more items rated as easier to remember than items rated as hard to remember. These results indicate that predictively useful JOLs can be made on reasonably homogeneous material. These judgments are not restricted to easily differentiated stimuli. The results suggest that JOLs are sensitive to various characteristics of the stimuli, a conclusion that agrees with other results showing a multicomponential basis for JOLs (Leonesio \& Nelson, 1988).

In addition, JOLs are affected by learning (and/or by an increased knowledge of the entire list), and these ratings change after study (Experiment 2). This change occurred primarily with the difficult-to-remember items, which were identified better after restudy than before restudy. Ratings of nonrecalled items dropped substantially after restudy, whereas ratings of recalled items showed only a slight increase.

Caution is required before concluding that the subjects were able to give correct JOLs, and that they were coherent in their use. The subjects might have remembered and repeated their recall output to be consistent with their JOL ratings. This explanation seems doubtful because the relationship was absent in some conditions (see the SR group in Experiment 1). Furthermore, the instructions stressed the importance of recalling as much as possible rather than giving accurate predictions, and in the postinterview, the subjects confirmed that the instructions were interpreted correctly. ${ }^{2}$

The experiments showed different patterns of time allocation. In Experiment 1, more time was devoted to studying items rated as intermediate in difficulty, whereas in Experiment 2, more time was allocated for studying items rated as difficult to remember. With $8 \mathrm{sec}$ of presentation (Experiment 1) and, partially, with $7.5 \mathrm{sec}$ (Experiment 3, Condition 3), subjects devoted the most study time to items rated as uncertain (i.e., intermediate in difficulty), whereas with $2.5 \mathrm{sec}$ of study time (Experiment 2 and, in part, Condition 1 of Experiment 3), items rated as most difficult to remember were studied longest.

Given that the subjects knew the phases of the experiment, ratings could have included an estimation of the study time required by the item. Nevertheless, the fact that study times did not always correspond to ratings suggests that the subjects gave ratings at least partially independently from such estimations. Introducing a second JOL in Experiment 2, after restudy, we found that JOL changes after restudy, being more discriminative for hardto-remember items. This result could explain why, after a long presentation time, subjects allocate more time to studying items rated as intermediate. If, after the long presentation time, subjects realize that the most difficult items are too hard to be learned, they may decide not to waste their time trying to learn those items, and may instead allocate that time to items judged as easier to remember. After a short presentation time, the state of the items may not be as clear, and harder items may be studied longer than easier items for two reasons: (1) some of the restudy time is spent determining the item's actual difficulty, and (2) it is not yet clear that the items are too hard to learn. Note that the different study-time allocation after a longer presentation time may not be more effective, given that no clear difference was found on recall between different presentation times.

Further research and theoretical analysis are required to determine the conditions and variables that affect subjects' decisions to stop the study phase. From a logical point of view, and on the basis of our postinterviews, we can observe that such a decision can be influenced by the evaluation of characteristics of both the memorization and the retrieval conditions. With respect to retrieval evaluations, subjects probably use information and metacognitive concepts about the requirements of a "well-memorized" item (e.g., it should be "well encoded," related to other information already in memory, familiar to the subject, etc.). With respect to the memorization phase, retrieval requirements could be compared with the characteristics of the specific item; the evaluation of the match between retrieval requirements and item characteristics increases 
progressively as the memorization process continues. At the same time, the test constraints could lead to a costbenefit comparison.

All three experiments lead us to conclude that the amount of study time per se does not increase recall. A similar result was obtained in a recent study (IntonsPeterson \& Smyth, 1987), in which phrases studied extensively by expert and novice readers were not perfectly recalled. In our procedure, the subjects tended to allocate more time to the items they were unsure of recalling (Experiment 1 and Experiment 3, Condition 3) or to the items they were almost sure of not recalling (Experiments 2 and 3). In these conditions, study effectiveness can be revealed by a "complete compensation" of recall of items with intermediate (3) or low (1-2) JOL ratings. This would occur if the amount of recall for the low-rated items was equivalent to the recall of high-rated items. However, this did not occur in any of our experiments. Our data also suggest that, when JOLs were equal for different items, recall of words and sentences was independent of the amount of restudy time. This does not mean that study time is not useful for increasing the overall level of recall (e.g., some low-rated items might have been recalled even worse without restudy), but that the extra study time did not completely compensate for the initial differences in recallability. One possible reason for why the subjects did not use enough time for hard-to-recall items is that their JOLs were not accurate enough to guide time allocation. That is, the subjects mistakenly judged the difficult-to-recall items as easy to recall immediately after the restudy time.

A similar result was recently obtained in a study not yet published (Nelson \& Leonesio, 1988), which we were not aware of when we carried out our experiments. Using different material and a different procedure, those authors showed that study time did not influence the probability of recalling items, an effect they labeled "the labor in vain." The lack of a compensation effect of study time is thus confirmed across material and procedures. Such results could be due to the short available total time to study items judged as difficult to recall. Nevertheless, recent results, not yet published, show that much longer time is also ineffective in leading to better recall. Further research, however, is required to determine the processes and factors that affect how self-paced study time influences recall, and to assess whether the length of the maximum time available and less compelling instructions for study-time use can change time-allocation strategy and effectiveness.

\section{REFERENCES}

ARBUCKLE, T. Y., CuddY, L. L. (1969). Discrimination of item strength at time of presentation. Journal of Experimental Psychology, 81, 126-131.

Bortolini, U., Tagliavini, C., \& Zampolli, A. (1972). Lessico di frequenza della lingua italiana contemporanea. Milan: Garzanti.

BRown, A. L. (1978). Knowing when, where and how to remember: A problem of metacognition. In R. Glaser (Ed.), Advances in instructional psychology (Vol. 1, pp. 77-165). Hillsdale, NJ: Erlbaum.
GaRdiner, J. M., \& KLEe, H. (1976). Memory for remembered events: An assessment of output monitoring in free recall. Journal of Verbal Learning \& Verbal Behavior, 15, 227-233.

GlucksBerG, S., \& MCCloskey, M. (1981). Decision about ignorance: Knowing that you don't know. Journal of Experimental Psychology: Human Learning \& Memory, 7, 311-325.

Groninger, L. D. (1979). Predicting recall: The feeling-that-I-willknow phenomenon. American Journal of Psychology, 92, 45-58.

HarT, J. T. (1965). Memory and the feeling-of-knowing experience. Journal of Educational Psychology, 56, 208-216.

Intons-Peterson, M. J., \& SMYth, M. M. (1987). The anatomy of repertory memory. Journal of Experimental Psychology: Learning. Memory, \& Cognition, 13, 490-500.

KeSTNER, J., \& WALTER, D. A. (1977). Awareness and the effect of rote rehearsal on free recall. American Joumal of Psychology, 90. 29-37.

King, J. F., Zechmeister, E. B., \&haughnessy, J. J. (1980). Judgements of knowing: The influence of retrieval practice. American Journal of Psychology, 93, 329-343.

Koriat, A., \& Lieblich, I. (1977). A study of memory pointers. Acta Psychologica, 41, 151-164.

LEONESIO, R. J., \& NELSON, T. O. (1988). A comparison of three measures of metamemory: Ease-of-learning judgments, judgments of knowing and feeling of knowing judgments. Unpublished manuscript.

LOVELACE, E. A. (1984). Metamemory: Monitoring future recallability during study. Journal of Experimental Psychology: Learning. Memory, \& Cognition, 10, 756-766.

Masur, E. F., Mclntyre, C. W., \& Flavell, J. H. (1973). Developmental changes in apportionment of study time in a multitrial free recall task. Joumal of Experimental Child Psychology, 15, 237-246.

Mazuryk, G. F., \& Lockhart, R. S. (1974). Negative recency and levels of processing in free recall. Canadian Joumal of Psychology, 28, 114-123.

Murdock, B. B., JR. (1974). Human memory: Theory and data. Potomac, MD: Erlbaum

Nelson, T. O. (1988). Predictive accuracy of the feeling of knowing across different criterion tasks and across different subject populations and individuals. In M. M. Gruneberg, P. E. Morris, \& R. N. Sykes (Eds.), Practical aspects of memory: Current research and issues (pp. 190-196). Chichester, England: Wiley.

NELSON, T. O., \& LEONESIO, R. J. (1988) Allocation of self-paced study time and the "labor-in-vain effect." Journal of Experimental Psychology: Learning, Memory, \& Cognition, 14, 676-686

Nelson, T. O., Leonesio, R. J., Shimamura, A. P., Landwehr, R. S. \& NARENS, L. (1982). Overlearning and the feeling of knowing. Journal of Experimental Psychology: Learning, Memory, \& Cognition, 8, 279-288.

Paivio, A., Yuille, J. K. C., \& Madigan, S. A. (1968). Concreteness, imagery and meaningfulness values for 925 nouns. Journal of Experimental Psychology Monographs, 76(1, Pt. 2).

Posnansky, C. J. (1978). Age- and task-related differences in the use of category-size information for the retrieval of categorized items. Journal of Experimental Child Psychology, 26, 373-382.

Pressley, M., Levin, J. R., \& Ghatala, E. S. (1984). Memory strategy monitoring in adults and children. Joumal of Verbal Learning \& Verbal Behavior, 23, 270-288.

Reder, L. M. (1987). Strategy selection in question answering. Cognitive Psychology, 19, 90-138.

Rogoff, B., Newcombe, N., \& Kagan, J. (1974). Planfulness and recognition memory. Child Development, 45, 972-977.

SCHNEIDER, W. (1985). Developmental trends in the metamemorymemory behavior relationship: An integrative review. In D. L. ForrestPressley, G. E. MacKinnon, \& T. G. Waller (Eds.), Metacognition, cognition and human performance (Vol. 1, pp. 57-109). New York: Academic Press.

Shaughnessy, J. J. (1981). Memory monitoring accuracy and modification of rehearsal strategies. Journal of Verbal Learning \& Verbal Behavior, 20, 216-230.

UNDERWOOD, B. J. (1964). Degree of learning and the measurement of forgetting. Journal of Verbal Learning \& Verbal Behavior, 3 , 112-129. 
UNDERWOOD, B. J. (1966). Individual and group predictions of item difficulty for free learning. Joumal of Experimental Psychology, 71, 673-679.

Waugh, N. C. (1967). Presentation time and free recall. Joumal of Experimental Psychology, 73, 39-44.

Wellman, H. M. (1979). The role of metamemory in memory behavior: A developmental demonstration. Unpublished manuscript, University of Michigan, Ann Arbor.

ZACKS, R. T. (1969). Invariance of total learning time under different conditions of practice. Journal of Experimental Psychology, 82, $441-447$.

\section{NOTES}

1. The significant interactions of groups $\times$ task $[F(2,32)=6.63$, $p=.015]$ and groups $\times$ task $\times$ ratings $[F(2,64)=4.00, p=.022]$ could indicate that the rating-plus-study condition improves recall if presented first, as in the SR group; however, the groups $\times$ task $\times$ ratings interaction has to be attributed to the SR group's restudy of the words rated as difficult to remember. The strange pattern of recall found for the SR group, which recalled $70 \%$ of the items judged difficult to recall, can be due to various factors, such as the low proportion of items with a low rating, a noise effect, or the effectiveness of restudy. Should the latter hypothesis be true, we could expect that items rated as less recallable should be studied for more time than those rated as uncertain, and that the more studied items should be recalled as well as the less studied ones (for the rationale of this prediction, see the introduction). However, in both cases, we obtained the opposite result. We cannot exclude that the result was due to a highlighting effect, because the percentage of words rated 1 and 2 was lower, although not significantly, than in the other groups and conditions (22\%, compared with a mean percentage of $31 \%$ for all the other cases); it is also possible that other noise variables contributed to this result.

2 . The data could also be explained on the basis of an outputinterference effect, due to a prior recall of the items judged easy to recall interfering with the postponed retrieval of hard-to-recall items. Nevertheless, our observations are in a different direction.

On the basis of the available protocols in which the recall order was registered (Experiment 2), we observed a slight tendency to retrieve first items rated 1 and 2. Dividing the recall protocol into three parts on the basis of the recall order, items rated 1 and 2 appeared 26 times in the first part, 14 times in the intermediate part, and 17 times in the final part of the recall list, whereas items rated 4 and 5 appeared, respectively, 27, 40, and 34 times.

(Manuscript received November 20, 1987;

revision accepted for publication August 7, 1989.) 